\title{
"WONDER BOYS" BOOK VS MOVIE COMPARISON: DO WONDER BOYS WANDER THROUGH JOYS?
}

\author{
Teodora LEON \\ Universitatea din București, România
}

Comparisons between books and movies tend to instigate intense conversations. Adapting a film is no simple task, but contrasting the two products can also be an erratic process, regardless of how much one tries to gather all of their ideas together. A mere observation can bring about diverse opinions or daring suggestions on how readers / viewers would have portrayed a certain scene or a small but crucial detail. In the end, it comes down to the charm of taking on the active role of a "critic" and analyzing the choices that were made alongside possible alternatives. The respective article will talk about how the novel "Wonder Boys", written by Michael Chabon, came to be interpreted in a different medium, as a comedy-drama film from 2000, directed by Curtis Hanson. "Wonder Boys" may be perceived as a world of freedom from various outlooks. In 1995, Chabon - already ahead of his time - produced a small universe in his novel, where his characters could express themselves candidly. In 2000, Hanson went from being a reader to an avid interpreter and creator of his own "Wonder Boys". Up until today, fortunate people, who come across the book and the film, can spot the director's ingenious approach, accompanied by his constant loyalty to the writer's concepts. We are dealing with a piece of work which should be discussed more frequently in classrooms or university lectures, due to its representative teacher-student bonding, the twisted realistic world - in which troubled individuals can still become inspirations for others - and its quality to be replicated in such inventive ways.

Keywords: comparison, movie adaptation, medium, freedom, reader, interpreter.

Movie adaptations have proven to be one of the most thrilling challenges any director could ever take on. Coming up with a story does imply its own demands, but the stakes are definitely higher when one decides to reinterpret somebody else's tale - additionally in a completely different medium. A transition from one medium to another is an element of fun in a creative world, but this whole procedure presupposes an open-minded film director who understands an author's message within their book and knows how to preserve it in a new creation, while also adding their personal touch. Many people may ask themselves why some wish to take such a risk or how they choose which books should have their stories on screen. Naturally, bestseller novels are the ones promising some suitably commercial adaptations. This is the key feature and yet, movie directors are cautious and opt for narratives which caught their attention in the first place. It is not always a matter of indulging in riches, but rather a bold desire to play with some switches. In this respect, the following article aims to discuss some of the main similarities and differences between Michael Chabon's novel called Wonder Boys and Curtis Hanson's 2000 adaptation, and simultaneously identify whether there is a medium allowing the main characters to wander through the most joys.

Out of the numerous possibilities, Wonder Boys demonstrated to be a plausible and intriguing option through its intricate - and paradoxically 
straightforward - world, which two different creators had to work with. The plot follows Grady Tripp - a novelist and a Creative Writing professor at an arts college in Pittsburgh - throughout the course of an eventful weekend. He gets tangled up in a pile of mess involving his wife's definite departure, his girlfriend's pregnancy confession, a dead dog, a stolen Marilyn Monroe jacket and a car stalker. Meanwhile, Grady forms an unexpected bond with one of his students, James Leer, a damaged individual, not adapted to social contexts, but incredibly gifted with words, being capable to produce gripping stories in a short amount of time. To have the atmosphere properly stirred up, Tripp's editor, Terry Crabtree, also comes into town and attends the university's literary conference, WordFest, as a pretext for his wish to look over Grady's latest novel, (un)surprisingly entitled Wonder Boys. These external conjunctions ignite insupportable internal concussions, oppressed in the initial stage, but eventually requiring Professor Tripp to take control and make choices.

Before delving into further details, an involuntary connection between Grady Tripp and movie director Curtis Hanson can already be distinguished. Keeping in mind the above-mentioned observation that the Professor is often needed to make choices, we can consider a remark made by Linda Seger in her book called The Art of Adaptation: Turning Fact and Fiction Into Film:

Adaptation demands choice. (...) Events might have to be refocused. Characters who carried a great deal of weight in the book might be deemphasized. If an important plot line doesn't serve the dramatic movement of the story, it could be dropped. With all these changes resonances may be lost, but the focus of the story lines may be strengthened. (9)

Readers, as well as viewers, are stepping into a realistic environment filled with decisions. It is compelling to track whether the main character limits the director's freedom of choice in the process of adaptation or it's the other way around. Should it be the latter, then how much can the producer rethink and intervene in the hero's mind without losing the principal essence? In a situation as such, a fair approach would be to claim that both the character and the director are bound to equally affect each other's choices and final solutions. Ultimately, in Wonder Boys, Curtis Hanson had to comprehend Grady Tripp's possibilities and Michael Chabon's motives hidden among the lines, and examine his own viable directorial paths.

It goes without saying that one's perception of characters can be different, depending on whether they choose to read the book or watch the movie first. Should someone discover Wonder Boys via the 2000 film, they will most likely end up feeling at peace with the development. On the other hand, the novel will have its newbies gawping at countless authentic, moderately detailed paragraphs and perhaps wishing to hear more from the protagonist. It may actually be advisable for people to start off the journey with the book. Afterwards, the movie will help them observe the director's freedom of combining scenes and adding clever segments, simultaneously remaining true to the author's plain intentions.

With these being said, the notion of "wonder boy" can be brought forward. The term itself refers to a person who achieves success effortlessly and does not have the ability to either analyze their talent or replicate it. This phenomenon is first suggested indirectly in the following paragraph of the novel: 
He's writing his name in water," I said. "What's that?" It was the halfregretful term - borrowed from the headstone of John Keats - that Crabtree used to describe his own and others' failure to express a literary gift through any actual writing on paper. Some of them, he said, just told lies; others wove plots out of the gnarls and elf knots of their lives and then followed them through to resolution. That had always been Crabtree's chosen genre thinking his way into an attractive disaster and then attempting to talk his way out, leaving no record and nothing to show for his efforts but a reckless reputation... (Chabon, 93)

Through this example, we notice how Michael Chabon depicts his story through the eyes of a writer who has just passed his own experience onto the main character and can unashamedly joke at his own expense in a similarly heartbreaking and ironic manner. In a book named Adaptations: From Text to Screen, Screen to Text, the introduction written by Imelda Whelehan features a comment which summarizes how the reader may initially feel about Chabon's unfolding path, before watching the movie: "There is still the preconception that the novelist produces a work of quality, of 'high' art as it emerges from the solitary efforts of the individual to express their distinct vision, untrammelled by concerns about the commercial value of the product which is deemed subsidiary to aesthetic value." (6). The phrase "it emerges from the solitary efforts of the individual" should be emphasized the most. Surely, along with the term "preconception", it can be stated that movie directors also create their own path and deserve as much acknowledge as writers. Such efforts are available in the case of Curtis Hanson, who preserves the general ambience, introduces his small but witty alterations and reminds the audience - in an exclusive interview - that "wonder boys" can be found in any context. In the upcoming part of the article, we shall go through the three main characters in Wonder Boys - from least to most active throughout the story - and determine the manner in which they get to step out from the book's pages, onto the big screen.

It is empowering to behold characters standing on their own two feet, both literally and figuratively, therefore an "aura of independence" may be first spotted at Terry Crabtree. In the book, he seems to be a desperate editor marching at the same pace as his old friend, Grady: "Crabtree's visit, viewed properly, was a kind of creative accident, a gift from God, a hammer blow to loosen all the windows my imagination had long since painted shut. I would finish it sometime tomorrow, hand it over to Crabtree, and thus save both our careers." (Chabon, 134). However, on the screen, he puts on the highly deserved show, diverging from the hopeless path and indicating more clearly he can be full of surprises if he's offered the much needed spark. Curtis Hanson does draw inspiration from Michael Chabon's occasional descriptions and reveals a character that knows at all times what could be going on behind his back and startles James Leer with his serpentine alluring actions:

As I talked about James and his book, Crabtree seemed to grow convinced not only that the young man must be a good writer - he gave "The Love Parade" a quick editorial flip-through on the way out, reading by the light from the glove box - but that he, Terry Crabtree, Agent of Chaos, was the 
switch failure on the tracks toward which James Leer's train was inexorably hurtling. (Chabon, 266)

Overall, Robert Downey Jr's Crabtree is tempting with his facial expressions, "an air of cool and unconcerned appraisal", and similarly confusing with his sudden mood switches, but he still ensures that everyone is in for a treat at every step.

As the editor is left searching for his upcoming hit to publish, young James Leer may turn heads, for his shyness and gloomy issues do not mark an inauspicious future. His bundle of lies, naturally constructed, can't make anyone angry, but rather perplexed, eager to witness the student's muddled walk. James, skillfully played by Tobey Maguire, often hears harsh commentary from surrounding voices, with concomitant questions such as, "Is your reality made up of false stories? Or are your stories inspired from reality?" Michael Chabon does not fully motivate the boy's attitude resembling an "alien probe". His character can laugh at anything for whatever reason and be as solitary as he desires. In the movie, though, there are two key scenes which introduce new perspectives.

\section{1) Q.'s petty speech, Y tryin' to teach?}

At WordFest, a writer recurrently known as Q. holds a lecture in a full auditorium. Chabon and Hanson go for separate speech topics, both of them leaving Grady and James baffled and bored. In the novel, the atmosphere is narrated passively by a drunk Grady "having a tough time concentrating on his words". The main theme is briefly mentioned, the reader is not supposed to pay a lot of attention to this aspect:

It seems to me that $Q$. was talking about the nature of the midnight disease, which started as a simple feeling of disconnection from other people, an inability to "fit in" by no means unique to writers (...). Very quickly, though, what happened with the midnight disease was that you began actually to crave this feeling of apartness, to cultivate and even flourish within it. You pushed yourself farther and farther and farther apart until one black day you woke to discover that you yourself had become the chief object of your own hostile gaze. (Chabon, 76)

The abrupt element is James' laugh in a still environment, a laugh "out loud, at some private witticism that had bubbled up from the bottom of his brain". The reader is not certain whether he has found something foolish in Q.'s words or has thought of something completely unrelated. In the movie, Curtis Hanson has decided to contextualize the bizzare burst, therefore the entire auditorium holds James' echoing laugh immediately after Q. states the following: "I am a writer. As a writer, you learn that everyone you meet has a story. Every bartender, every taxi driver has an idea that would make a great book. Presumably, each of you has an idea. But how do you get from there to here? What is the bridge from the water's edge of inspiration to the far shore of accomplishment?" (Wonder Boys, 26:46). The cryptic student may slightly become more relatable, viewers finally detecting his disapproval of Q.'s foolishly nonchalant stance. This qualifies as one of the most important insights into James' mentality.

\section{2) Style the writing, pile the emotions!}


The boy's world is once again intruded into when Grady and Terry go to James' house. The real "break-in" occurs when the two friends come across his compositions. Chabon builds up a somewhat envious Tripp who reads James' work and later admits sincerely he may begin to lose Crabtree when the student takes his place as the new promising writer: "At the sight of James in Crabtree's jacket I experienced a sharp pang of abandonment (...). I guess you could say that in a strange sort of way I'd always believed that Crabtree was my man, and I was his. It was only proper, I supposed, for the first thing in my life that had ever felt right to be the last one to be proven wrong." (Chabon, 338). Hanson seeks to transform the professor-student connection into something even more special and remind everyone that Grady has inspired his faithful student to write in the first place. Thus, the director gives Terry the significant job to find a paragraph written by James, which features an emotional apprehension based on a recent real-life interaction (the most honest words so far, given the boy's lies and messed-up perceptions):

Terry: Hey. Check this out. "Finally, the door opened. It was a shock to see him shuffling into the room like an aging prizefighter. Limping. Beaten." Does that sound like anyone we know? "But it was later, when the great man squinted into the bitter glow of twilight..." "Twilight", this kid definitely needs an editor. "... and muttered simply, 'It means nothing. All of it. Nothing.' that the true shock came. It was then that the boy understood that his hero's true injuries lay in a darker place. His heart, once capable of inspiring others so completely, could no longer inspire so much as itself. It beat now only out of habit. It beat now only because it could (Wonder Boys, $1: 17: 34)$.

James is never meant to be Grady's competition. The troubled teacher has no other option than to admit he struggles with writer's block (hence his neverending novel) in a delirious trance. Michael Douglas' Grady Tripp is once and for all under the spotlight and has one unique mission in each medium. Within Michael Chabon's pages, he explains himself to his loved ones (including Emily, his former wife, who doesn't even appear in the movie), reconsiders his actions, learns to take mature decisions (for writers make the most choices, after all) and declares he's had a worthwhile impact on his students, despite his pestering issues from the last couple of years. In Curtis Hanson's eyes, he sticks to the same principle, but he also subconsciously connects to James a whole lot more. Chabon almost presents Professor Tripp as being left out for a while, perhaps even forgotten by the young student, which would come off as an unfair move.

Reconciliation is sought (and found) in many places and it is truthfully felt in one last touching scene. Overall, Grady has to come to terms with his evolution and that happens symbolically when James' novel, The Love Parade, gets published. In the movie, in a packed auditorium, the teacher has the opportunity to proudly shout, "Take a bow, James!" (contrary to the book, in which another fellow student says that), and oficially "initiate" his apprentice into the world of admirable accomplishments and reasonable failures by passing on the wondrous title of "wonder boy".

It would not be fair to point out that Curtis Hanson did a better job than Michael Chabon or vice versa. Both universes are to be praised for their distinct 
approaches and redeeming experiences set up for a group of wonder boys. The author clearly prefered to tread behind Grady and guide him through twisted encounters, whereas the director felt the need to illustrate the main characters equally. Readers and viewers altogether will distinguish the common trait: everyone may be a wonder figures in their own ways, with temporary sadness rooted in their suspicions, but permanent hope concealed in their redefinitions.

\section{Bibliographical references}

Cartmell, Deborah and Imelda Whelehan. <<Adaptations: The contemporary dilemmas〉>, Adaptations: From Text to Screen, Screen to Text. New York: Routledge, Taylor \& Francis Group, 2005.

Chabon, Michael. Wonder Boys. New York: Random House Trade Paperbacks, 2008.

Seger, Linda. The Art of Adaptation: Turning Fact and Fiction Into Film. New York: Henry Holt and Company, 1992. 